\title{
ANALISIS POSTUR KERJA PENAMBANG PASIR KECAMATAN BUKIT KAPUR KOTA DUMAI
}

\author{
Muhammad Yoga \\ Pratama $^{(1)}$, Trisna Mesra ${ }^{(2)}$, \\ Rudi Faisal $^{(3)}$ \\ ${ }^{1)}$ Program Studi Teknik Industri, Sekolah \\ Tinggi Teknologi Dumai \\ Jl. Utama Karya Bukit Batrem II \\ Email: yoga53476@gmail.com; \\ trisnamesra74@gmail.com; \\ faisalrudifaisal@gmail.com
}

\begin{abstract}
ABSTRAK
Salah satu penambangan pasir yang ada dikota Dumai adalah milik Bapak Sukatno yang berada di jalan Pasir kecamatan Bukit Kapur. Pekerja penambangan pasir ini ada 3 bagian, yaitu pekerja yang mengarahkan pipa pada saat menghisap pasir ke bak penampungan pasir, pekerja yang menyaring pasir ke bak penampungan pasir dan pekerja penyekop pasir ke bak mobil. Pekerja penyekop pasir merupakan yang paling rentan terkena cidera otot karena pekerjaannya lebih berat dari ketiga pekerjaan tersebut. Kuesioner Nordic Body Map (NBM) digunakan untuk mengetahui cedera Musculoskeletal Disorders yang dialami pekerja. Ssedangkan untuk mengetahui tingkat risiko cedera pekerja menggunakan metode Rapid Entire Body Assessment (REBA). Hasil NBM yang paling berisiko cidera pada pekerja adalah leher bawah, bahu kanan, lengan atas kiri, punggung, lengan atas kanan, pinggang, lengan bawah kanan, pergelangan tangan kiri, tangan kiri, tangan kanan. Tingkat risiko untuk postur memijak sekop, mengangkat sekop dan mengayunkan sekop pada saat penampungan pasir penuh adalah sedang dengan level risiko 4-6 dan saat penampungan pasir setengah adalah sedang dengan level risiko 4-7. Sedangkan tingkat risiko untuk postur melempar pasir ke bak mobil pada saat penampungan pasir penuh tingkat risiko rendah dengan level risiko 3 dan saat penampungan pasir setengah adalah rendah dengan level risiko 2 dan 4 .
\end{abstract}

Kata-kunci: Musculoskeletal disorders, Nordic Body Map,

Penambang, Rapid Entire Body Assesment.

\section{ABSTRACT}

One of the sand mining in dumai city belongs to Mr. Sukatno who is on pasir street bukit kapur subdistrict. This sand mining worker has 3 parts, namely workers who direct pipes when sucking sand into sand reservoirs, workers who filter sand into sand reservoirs and sand shovel workers to car tubs. Sand shoveling workers are the most vulnerable to muscle injuries because their work is heavier than all three jobs. Nordic Body Map (NBM) questionnaire used to find out musculoskeletal disorders suffered by workers. As for knowing the level of risk of injury workers using the Rapid Entire Body Assessment (REBA) method. NBM results most at risk of injury to workers are the lower neck, right shoulder, left upper arm, back, right upper arm, waist, right forearm, left wrist, left hand, right hand. The risk level for the posture of stepping on a spade, lifting a shovel and swinging a shovel at the time of full sand shelter is moderate with a risk level of 4-6 and when the sand reservoir is half is moderate with a risk level of 4-7. While the risk level for the posture of throwing sand into the car tub at the time of the sand reservoir is full the level of risk is low with a risk level of 3 and when the sand reservoir is half is low with risk levels 2 and 4.

Keywords: Musculoskeletal disorders, Nordic Body Map, Miners, Rapid Entire Body Assessment. 


\section{Pendahuluan}

Sumber daya alam adalah semua potensi dan lingkungan yang dapat memenuhi kebutuhan hidup manusia. Salah satu sumber daya alam yang penting bagi kehidupan manusia adalah bahan galian seperti pasir. Pasir ini sangat diperlukan untuk bahan pembangunan insfrastruktur seperti gedung, jalan serta kegiatan industri lainnya. Salah satu penambangan pasir yang ada dikota Dumai yaitu milik Bapak Sukatno yang berada di jalan Pasir kecamatan Bukit Kapur. Pekerja di penambangan pasir tersebut merupakan warga sekitar yang sudah bekerja selama bertahun-tahun. Pekerja penambangan pasir ini ada 3 bagian, yaitu pekerja yang mengarahkan pipa pada saat menghisap pasir ke bak penampungan pasir, pekerja yang menyaring pasir ke bak penampungan pasir dan pekerja penyekop pasir ke bak mobil.

Pekerja penyekop pasir merupakan yang paling rentan terkena cidera otot karena pekerjaannya lebih berat dari ketiga pekerjaan tersebut. Pekerja penyekop pasir di penambangan pasir Kecamatan Bukit Kapur, Kota Dumai masih menggunakan cara manual. Oleh sebab itu pekerjaan secara manual sangat berisiko mengalami gangguan MSDs (Musculoskeletal Disorders). Postur tubuh yang kurang baik saat bekerja dapat menimbulkan terjadinya gangguan pada rangka tubuh dan sistem otot yang disebut dengan Musculoskeletal Disorders (MSDs). Kelelahan dini pada pekerja-pekerja juga dapat menimbulkan penyakit akibat kerja dan kecelakaan kerja yang mengakibatkan cacat bahkan kematian. Selain kerugian secara fisik juga menyebabkan kerugian secara materi melalui beban biaya pengobatan yang cukup tinggi. Serta ketidakhadiran pekerja dapat menurunkan dalam kualitas kerja.

Hasil kuesioner NBM (Nordic Body Map) yang telah disebar, didapati ada beberapa keluhan yang dirasakan oleh pekerja penyekop pasir yang berjumlah 2 orang. Persentase sakit pada leher atas adalah 50\%, leher bawah 100\%, bahu kiri 50\%, bahu kanan $100 \%$, lengan atas kiri 100\%, punggung 100\%, lengan atas kanan 100\%, pinggang $100 \%$, lengan bawah kiri $100 \%$, lengan bawah kanan 100\%, pergelangan tangan kiri $100 \%$, pergelangan tangan kanan 50\%, tangan kiri $100 \%$, tangan kanan $100 \%$, betis kiri $50 \%$, kaki kiri 50\%. Rasa sakit (capek atau lelah) berpotensi cedera pada bagian tubuh tertentu karena beban kerja tidak sesuai dengan kemampuan pekerja. Penelitian ini dilakukan untuk mengetahui tingkat risiko cidera pada pekerja penyekop dengan menggunakan metode REBA (Rapid Entire Body Assessment). REBA adalah sebuah metode dalam bidang ergonomi yang digunakan secara cepat untuk menilai postur leher, punggung, lengan, pergelangan tangan dan kaki seorang pekerja. Berdasarkan masalah yang telah ada, maka peneliti mengambil judul "Analisis Postur Kerja Penambang Pasir Kecamatan Bukit Kapur Kota Dumai”.

\section{Metode Penelitian}

Teknik pengumpulan data pada penelitian ini adalah data dari keluhan pekerja menggunakan kuesioner Nordic Body Map (Supriyanto, 2011) yang terdiri dari 2 bagian, yaitu bagian identitas pekerja dan bagian kuesioner. Sampel yang diambil sebanyak 6 orang tenaga kerja berdasarkan keluhan yang dirasakan. Data yang telah dikumpulkan dapat diolah dengan menggunakan metode REBA. Pada tahap awal pengambilan data, dilakukan dengan merekam kegiatan pekerja dan mengambil fotonya. Kemudian dilakukan pengolahan data dengan mengukur menggunakan busur 
derajat untuk mengetahui sudut pada postur tubuh pekerja. Setelah itu dilakukan perhitungan menggunakan metode REBA.

\section{Hasil dan Pembahasan}

\section{Data Umum Pekerja}

Adapun identitas pekerja dapat dilihat pada Tabel 1.

Tabel 4.1. Data Umum Pekerja Penambang Pasir

\begin{tabular}{|c|l|c|c|c|c|}
\hline No & \multicolumn{1}{|c|}{ Nama } & $\begin{array}{c}\text { Usia } \\
(\text { Tahun })\end{array}$ & $\begin{array}{c}\text { Lama } \\
\text { Bekerja }\end{array}$ & $\begin{array}{c}\text { Tinggi Badan } \\
(\mathrm{cm})\end{array}$ & $\begin{array}{c}\text { Berat Badan } \\
(\mathrm{kg})\end{array}$ \\
\hline 1 & Rahmat & 39 & 8 Tahun & 173 & 68 \\
\hline 2 & Hendra & 37 & 5 Bulan & 177 & 65 \\
\hline
\end{tabular}

Sumber: Penelitian, 2020

\section{Postur kerja}

Postur yang diamati adalah penyekop pasir dipertambangan pasir kecamatan Bukit Kapur. Pekerjaan yang dilakukan dibedakan menjadi 2 klasifikasi, yaitu pada saat tempat penampungan pasir masih penuh dan pada saat tempat penampungan pasir tinggal setengah.

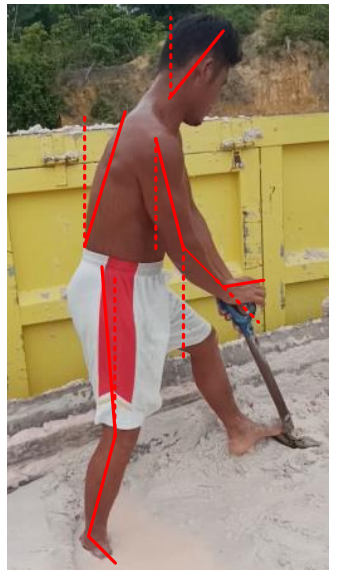

(a)

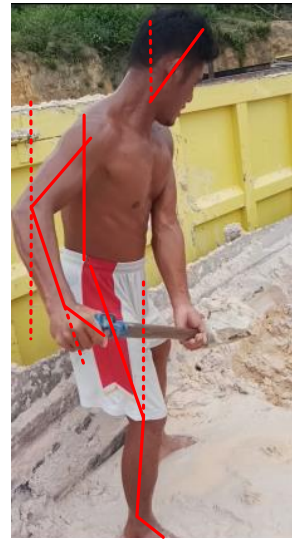

(c)
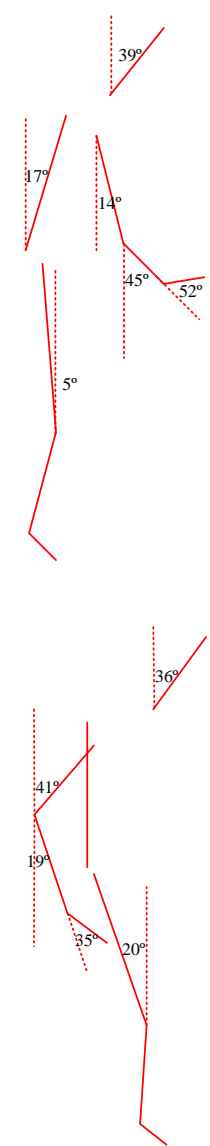

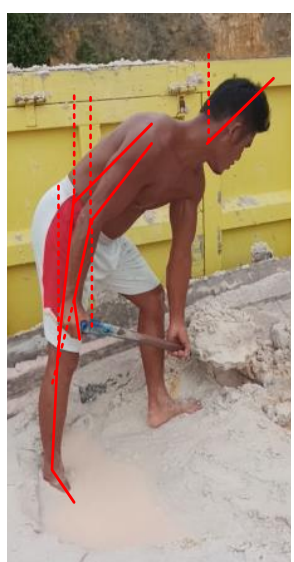

(b)
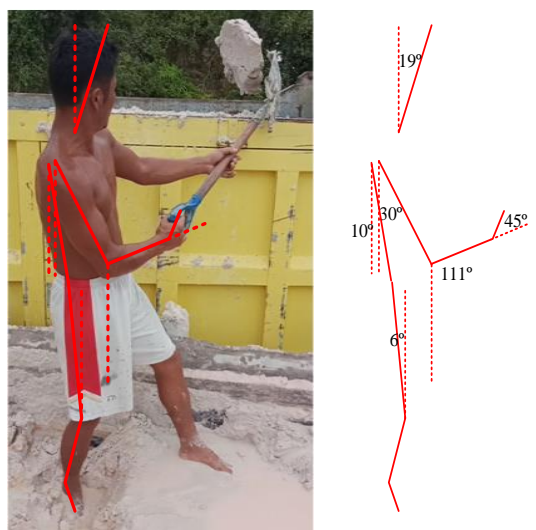

(d)

Gambar 1. Postur Pekerja 1, (a) memijak sekop; (b) mengangkat sekop;

(c) mengayunkan sekop; (d) melempar pasir ke bak mobil

Sumber: Data Pengamatan, 2020 
Tabel 2. Skor Pekerja 1 Memijak Sekop

\begin{tabular}{|c|l|l|c|}
\hline No & \multicolumn{1}{|c|}{ Kategori } & & Pergerakan \\
\hline 1 & Trunk & $17^{\circ}$ ke depan Skor \\
\hline 2 & Neck & $39^{\circ}$ ke depan & 2 \\
\hline 3 & Legs & Kedua kaki menahan berat tubuh & 2 \\
\hline 4 & Loadlforce & Kecil dari 5 kg & 1 \\
\hline 5 & Upper arm & $14^{\circ}$ ke depan & 0 \\
\hline 6 & Lower arm & $45^{\circ}$ ke depan & 1 \\
\hline 7 & Wrist & $52^{\circ}$ extension & 2 \\
\hline 8 & Coupling & Good & 2 \\
\hline 9 & Activity & Perulangan & 1 \\
\hline
\end{tabular}

Sumber: Pengolahan Data, 2020

Tabel 2 merupakan skor yang akan digunakan untuk menghitung tingkat risiko postur kerja menggunakan metode REBA. Penilaian skor A dapat dilihat pada Tabel 4.3.

Tabel 3. Penilaian Skor A Pekerja 1 Memijak Sekop

\begin{tabular}{|c|c|c|c|c|c|c|c|c|c|c|c|c|c|}
\hline \multirow{3}{*}{ Tabel A } & \multicolumn{13}{|c|}{ Neck } \\
\hline & \multirow[b]{2}{*}{ Legs } & \multicolumn{4}{|c|}{1} & \multicolumn{4}{|c|}{2} & \multicolumn{4}{|c|}{3} \\
\hline & & 1 & 2 & 3 & 4 & 1 & 2 & 3 & 4 & 1 & 2 & 3 & 4 \\
\hline \multirow{5}{*}{$\begin{array}{l}\text { Trunk } \\
\text { postur } \\
\text { score }\end{array}$} & 1 & 1 & 2 & 3 & 4 & 1 & 2 & 3 & 4 & 3 & 3 & 5 & 6 \\
\hline & 2 & 2 & 3 & 4 & 5 & 3 & 4 & 5 & 6 & 4 & 5 & 6 & 7 \\
\hline & 3 & 2 & 4 & 5 & 6 & 4 & 5 & 6 & 7 & 5 & 6 & 7 & 8 \\
\hline & 4 & 3 & 5 & 6 & 7 & 5 & 6 & 7 & 8 & 6 & 7 & 8 & 9 \\
\hline & 5 & 4 & 6 & 7 & 8 & 6 & 7 & 8 & 9 & 7 & 8 & 9 & 9 \\
\hline
\end{tabular}

Sumber: Pengolahan Data, 2020

Tabel 3 merupakan penilaian skor A pada pekerja 1 saat memijak sekop pada saat bak penampungan pasir penuh. hasil skor A yang didapat adalah 3 yang selanjutnya akan ditambahkan dengan skor beban yaitu 0 , sehingga hasilnya 3 .

Tabel 4. Penilaian Skor B Pekerja 1 Memijak Sekop

\begin{tabular}{|c|c|c|c|c|c|c|c|}
\hline \multirow{3}{*}{ Table $B$} & \multicolumn{7}{|c|}{ Lower Arm } \\
\cline { 2 - 8 } & & \multicolumn{7}{|c|}{1} & \multicolumn{4}{|c|}{2} \\
\cline { 2 - 8 } & \multirow{2}{*}{ Wrist } & \multicolumn{7}{|c|}{2} & 3 & 1 & 2 & 3 \\
\cline { 2 - 8 } & 1 & 1 & 2 & 2 & 1 & 2 & 3 \\
\hline \multirow{4}{*}{$\begin{array}{c}\text { Upper Arm } \\
\text { Score }\end{array}$} & 2 & 1 & 2 & 3 & 2 & 3 & 4 \\
\cline { 2 - 8 } & 3 & 3 & 4 & 5 & 4 & 5 & 5 \\
\cline { 2 - 8 } & 4 & 4 & 5 & 5 & 5 & 6 & 7 \\
\cline { 2 - 8 } & 5 & 6 & 7 & 8 & 7 & 8 & 8 \\
\cline { 2 - 8 } & 6 & 7 & 8 & 8 & 8 & 9 & 9 \\
\hline
\end{tabular}

Sumber: Pengolahan Data, 2020

Tabel 4 merupakan penilaian skor B pada pekerja 1 saat memijak sekop pada saat bak penampungan pasir penuh. hasil skor B yang didapat adalah 2 yang selanjutnya akan ditambahkan dengan skor coupling yaitu 0 , sehingga hasilnya 2. 
Tabel 5. Penilaian Skor C Pekerja 1 Memijak Sekop

\begin{tabular}{|c|c|c|c|c|c|c|c|c|c|c|c|c|}
\hline $\begin{array}{l}\text { Score } \begin{array}{l}\text { Score } \\
\text { (score from } \\
\text { table A }\end{array} \\
\begin{array}{l}\text { load/force } \\
\text { Score) }\end{array}\end{array}$ & 1 & 2 & 3 & 4 & 5 & 6 & 7 & 8 & 9 & 10 & 11 & 12 \\
\hline 1 & 1 & 1 & 1 & 2 & 3 & 3 & 4 & 5 & 6 & 7 & 7 & 7 \\
\hline 2 & 1 & 2 & 2 & 3 & 4 & 4 & 5 & 6 & 6 & 7 & 7 & 8 \\
\hline 3 & 2 & 3 & 3 & 3 & 4 & 5 & 6 & 7 & 7 & 8 & 8 & 8 \\
\hline 4 & 3 & 4 & 4 & 4 & 5 & 6 & 7 & 8 & 8 & 9 & 9 & 9 \\
\hline 5 & 4 & 4 & 4 & 5 & 6 & 7 & 8 & 8 & 9 & 9 & 9 & 9 \\
\hline 6 & 6 & 6 & 6 & 7 & 8 & 8 & 9 & 9 & 10 & 10 & 10 & 10 \\
\hline 7 & 7 & 7 & 7 & 8 & 9 & 9 & 9 & 10 & 10 & 11 & 11 & 11 \\
\hline 8 & 8 & 8 & 8 & 9 & 10 & 10 & 10 & 10 & 10 & 11 & 11 & 11 \\
\hline 9 & 9 & 9 & 9 & 10 & 10 & 10 & 11 & 11 & 11 & 12 & 12 & 12 \\
\hline 10 & 10 & 10 & 10 & 11 & 11 & 11 & 11 & 12 & 12 & 12 & 12 & 12 \\
\hline 11 & 11 & 11 & 11 & 11 & 12 & 12 & 12 & 12 & 12 & 12 & 12 & 12 \\
\hline 12 & 12 & 12 & 12 & 12 & 12 & 12 & 12 & 12 & 12 & 12 & 12 & 12 \\
\hline
\end{tabular}

Sumber: Pengolahan Data, 2020

Tabel 5 merupakan penilaian skor $\mathrm{C}$ pada pekerja 1 saat memijak sekop pada saat bak penampungan pasir penuh. hasil skor $\mathrm{C}$ yang didapat adalah 3 dan akan ditambahkan dengan skor aktivitas yaitu 1. Berdasarkan hasil penilaian tersebut, dapat secara singkat dijelaskan dalam bentuk gambar yang dapat dilihat pada Gambar 2.

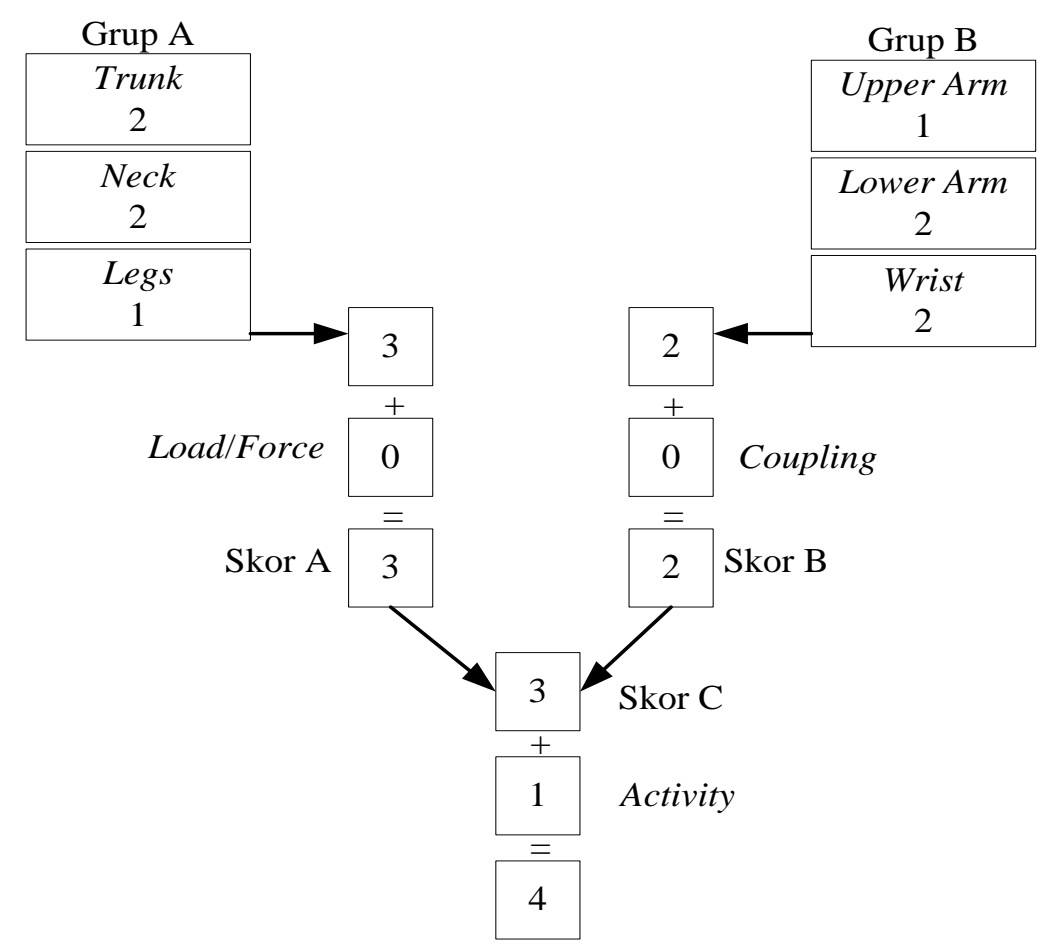

Gambar 2. Skor REBA Pekerja 1 Memijak Sekop

Sumber: Pengolahan Data, 2020 
Gambar 2 merupakan skor REBA yang diperoleh untuk postur pekerja 1 saat memijak sekop pada saat bak penampungan pasir penuh. Skor akhir REBA adalah 4 yang termasuk level sedang.

\section{Analisa Postur Tubuh}

Hasil analisis postur kerja dari semua pekerja dapat dilihat pada Tabel 6 berikut.

Tabel 6. Hasil Analisis Tingkat Risiko Pekerja

\begin{tabular}{|c|c|c|c|c|}
\hline No & $\begin{array}{l}\text { Tingkat } \\
\text { Risiko }\end{array}$ & $\begin{array}{l}\text { Jumlah } \\
\text { Pekerja }\end{array}$ & Postur & Action \\
\hline \multirow{3}{*}{1} & \multirow{3}{*}{ Rendah } & 2 & $\begin{array}{l}\text { Melempar pasir ke bak mobil pada saat } \\
\text { penampungan pasir penuh }\end{array}$ & \multirow{3}{*}{$\begin{array}{l}\text { Mungkin } \\
\text { diperlukan }\end{array}$} \\
\hline & & 1 & $\begin{array}{l}\text { Melempar pasir ke bak mobil pada saat } \\
\text { penampungan pasir setengah }\end{array}$ & \\
\hline & & 1 & $\begin{array}{l}\text { Mengayunkan sekop pada saat } \\
\text { penampungan pasir penuh }\end{array}$ & \\
\hline \multirow{7}{*}{2} & \multirow{7}{*}{ Sedang } & 2 & $\begin{array}{l}\text { Memijak sekop pada saat penampungan } \\
\text { pasir penuh }\end{array}$ & \multirow{7}{*}{ Diperlukan } \\
\hline & & 2 & $\begin{array}{l}\text { Mengangkat sekop pada saat } \\
\text { penampungan pasir penuh }\end{array}$ & \\
\hline & & 1 & $\begin{array}{l}\text { Mengayunkan sekop pada saat } \\
\text { penampungan pasir penuh }\end{array}$ & \\
\hline & & 2 & $\begin{array}{l}\text { Memijak sekop pada saat penampungan } \\
\text { pasir setengah }\end{array}$ & \\
\hline & & 2 & $\begin{array}{l}\text { Mengangkat sekop pada saat } \\
\text { penampungan pasir setengah }\end{array}$ & \\
\hline & & 2 & $\begin{array}{l}\text { Mengayunkan sekop pada saat } \\
\text { penampungan pasir setengah }\end{array}$ & \\
\hline & & 1 & $\begin{array}{l}\text { Melempar pasir ke bak mobil pada saat } \\
\text { penampungan pasir setengah }\end{array}$ & \\
\hline
\end{tabular}

Sumber: Pengolahan Data, 2020

\section{Kesimpulan}

Kesimpulan yang didapat untuk tingkat risiko yang dialami pekerja penyekop penambangan pasir di kecamatan Bukit Kapur kota Dumai dengan menggunakan metode REBA adalah rendah dan sedang. Tingkat risiko untuk postur memijak sekop, mengangkat sekop dan mengayunkan sekop pada saat bak penampungan pasir penuh adalah sedang dengan level risiko 4-6, sedangkan tingkat risiko untuk postur melempar pasir ke bak mobil pada saat penampungan pasir penuh tingkat risiko rendah dengan level risiko 3. Tingkat risiko untuk postur memijak sekop, mengangkat sekop dan mengayunkan sekop pada saat penampungan pasir setengah adalah sedang dengan level risiko 4-7, sedangkan tingkat risiko untuk postur melempar pasir ke bak mobil pada saat penampungan pasir setengah adalah rendah dengan level risiko 2 dan 4 . Untuk pekerja dengan level risiko rendah diperlukan tindakan beberapa waktu ke depan dan untuk pekerja dengan level risiko sedang tindakan dalam waktu dekat.

\section{Saran}

Saran yang dapat saya berikan adalah membuat bentuk gagang sekop yang lebih panjang agar pada saat menyekop badan tidak terlalu membungkuk ke bawah. 


\section{Daftar Pustaka}

Anthony, M.B., 2020. Analisis Postur Pekerja Pengelasan Di CV XYZ Dengan Metode Rapid Entire Body Assesment (REBA). JATI UNIK, Vol. 3, No. 2, ISSN: 25977946.

Astari, A., 2017. Gambaran Postur Kerja Petani Rumput Laut Dengan Metode REBA Di Pulau Kanalo Dua Kec Pulau Sembilan Kab Sinjai. Skripsi Sarjana Kesehatan Masyarakat, Universitas Islam Negeri Alauddin, Makassar.

Azmi, Fitra, dan Suroso, M., 2021, Penerapan Data Antropometri Dalam Perancangan Alat Pengupas Sabut Kelapa Ekonomis, Jurnal ARTI (Aplikasi Rancangan Teknik Industri), VOL.16 NO 1 (2021) Desember 2020 - Mei 2021, Hal: 94-99

Budhiman, M.A., 2015. Analisis Penilaian Tingkat Resiko Ergonomi Pada Pekerja Konstruksi Proyek Ruko Graha Depok. Skripsi Fakultas Kedokteran dan Ilmu Kesehatan, Universitas Islam Negeri (UIN) Syarif Hidayatullah, Jakarta.

Ernita, T., Ervil, R., dan Apriyan. R., 2020. Analisis Penilaian Resiko Gangguan Tubuh Pekerja Pada Pemindahan Buah Kelapa Sawit Dengan Menggunakan Metode REBA. Jurnal Sains dan Teknologi, Vol. 20, No. 1, Juni 2020, ISSN: 26152827.

Imron, M., 2019. Analisis Tingkat Ergonomi Postur Kerja Karyawan Di Laboratorium KCP Pada PT Steelindo Wahana Perkasa Dengan Metode Rapid Upper Limb Assesment (RULA), Rapid Entire Body Assesment (REBA) Dan Ovako Working Posture Analisys (OWAS). JITMI, Vol. 2, No. 2, Oktober 2019, ISSN 26856123.

Iridiastadi, H., dan Yassierli, 2014. Ergonomi Suatu Pengantar. PT Remaja Rosdakarya, Bandung.

Kurnia, F., dan Sobirin, M., 2020. Analisis Tingkat Kualitas Postur Pengemudi Becak Menggunakan Metode RULA Dan REBA. Jurnal Engine. Vol. 4, No. 1, Mei 2020, ISSN: 2579-7433

Mardiyanto, 2008. Analisa Postur Kerja Menggunakan Metode Rapid Upper Limb Assessment (RULA). Skripsi Sarjana Teknik Industri, Universitas Muhammadiyah, Surakarta.

Rahmawati, A., dan Utami, D.L., 2020. Analisa Postur Pengendara Motor Untuk Evaluasi Dimensi Bagian Tempat Duduk Dengan Menggunakan Metode REBA. Jurnal Untuk Masyarakat Sehat (JUKMAS). Vol. 4, No. 01, April 2020, ISSN: 2715-8748.

Supriyanto., 2011. Perancangan Postur Kerja Pada Pekerja Bagian Pencucian Dan Penggilingan Kedelai Dengan Pendekatan Rapid Entire Body Assessment (REBA) Untuk Mengurangi Risiko Musculoskeletal Disorders (MSDs). Skripsi Sarjana Teknik Industri, Universitas Sebelas Maret, Surakarta. 